\title{
EDUCAÇÃO DE POVOS E COMUNIDADES TRADICIONAIS: DA CONQUISTA DO DIREITO À CONSTRUÇÃO DA AÇÃO PEDAGÓGICA PARA A DIVERSIDADE ÉTNICA E CULTURAL
}

\author{
PEOPLES AND TRADICIONAL COMMUNITIES EDUCATION: \\ FROM CONQUERING THE RIGHT TO PEDAGOGICAL ACTION FOR ETHNIC \\ AND CULTURAL DIVERSITY
}

\section{EDUCACIÓN DE PUEBLOS Y COMUNIDADES TRADICIONALES: DE LA CONQUISTA DEL DERECHO A LA CONSTRUCCIÓN DE LA ACCIÓN PEDAGÓGICA PARA LA DIVERSIDAD ÉTNICA Y CULTURAL}

\section{Resumo}

O Curso de Licenciatura em Etnodesenvolvimento da Universidade Federal do Pará, ao longo dos 10 anos de fundação, tem possibilitado uma nova configuração do "fazer didático-pedagógico" da Educação de povos e comunidades tradicionais da Amazônia paraense. O presente estudo, consiste em uma reflexão acerca da relação entre os fundamentos teóricos, os métodos e o currículo do Curso com as demandas sociais provenientes da prática pedagógica, por meio da análise de dados coletados pelos próprios discentes da turma de Etnodesenvolvimento/2019 em pesquisas de campo nas suas comunidades de pertença quilombolas, indígenas, extrativistas, de pescadores e agricultores. Os dados analisados configuram a escola, nos diferentes territórios e com as diversas pertenças, como um espaço de disputa pelo: 1) direito ao reconhecimento do ensino instituido como "formal" pelo sistema de ensino ocidental; 2) entre os modelos de educação exógenos e expressões locais de projeto educativo; e 3) garantia das condições materiais e de infraestrutura para o funcionamento dos calendários letivos. Do mesmo modo, as pesquisas evidenciam os resultados positivos do processo de formação de etnoeducadores, os quais têm desenvolvido projetos de intervenção e autogestão das comunidades.

Palavras-chave: Etnodesenvolvimento. Amazônia. Educação.

\section{Abstract}

The degree in Etnodesenvolvimento Course from Pará Federal University, along 10 years of its foundation is accomplishing a new range of possibilities and configurations when it comes to "performing a didactic and pedagogic teaching" with traditional people and their communities from "paraense" Amazonian Education. This study concerns about the relation between fundamental theories, methods and the course curriculum, to attend social demands that comes from the pedagogical practice using collected and analyzed data by our own students from Etnodesenvolvimento class/2019 through field researches on their own communities namely quilombolas, indigenous people, natural resources collectors, fishers and plough people. The data analyzed sets up the schools located in various places with different belongings identity as a field claiming for: 1) legal rights and recognition for formal education in the patterns of western culture; 2) exogenous education models

\footnotetext{
${ }^{1}$ Doutora em Arqueologia. Professora da Faculdade de Etnodiversidade da Universidade Federal do Pará, Campus Altamira. e-mail: sousa.eliane@gmail.com

${ }^{2}$ Mestre em Linguagens e Saberes na Amazônia. Professora da Faculdade de Etnodiversidade da Universidade Federal do Pará, e-mail: portugaljessica@hotmail.com
} 
and local forms of expressions within education projects; and 3) assurance for infrastructure and material conditions for the operation of academic calendars. The same way, the researches point to positive results on the Ethno-educators academic training process, which are developing some mediations and self-management community projects.

Keywords: Etnodesenvolvimento, Amazonia, Education.

\section{Resumen}

El curso de Licenciatura en Etnodesarrollo de la Universidad Federal de Pará, a lo largo de sus 10 años de fundación, ha facilitado una nueva configuración de "un hacer didáctico pedagógico" en la educación de pueblos y comunidades tradicionales de la Amazonía de Pará. El presente estudio consiste en una reflexión acerca de la relación entre los fundamentos teóricos, los métodos y el contenido del Curso, con las demandas sociales provenientes de la práctica pedagógica, por medio del análisis de datos recogidos por los propios estudiantes del grupo de Etnodesenvolvimento 2019 en investigaciones de campo en sus comunidades de origen quilombas, indígenas, extractivistas, pescadores y campesinos (agricultores).. Los datos analizados configuran la escuela en los diferentes territorios y con los diferentes orígenes como un espacio de disputa por: 1) Derecho al reconocimiento de la enseñanza instituída como "formal" por el sistema de enseñanza occidental; 2) Entre los modelos de educación exógenos y expresiones locales de proyecto educativo; y 3) Garantía de las condiciones materiales y de infraestructura para el funcionamiento de los calendarios propios. Del mismo modo, las investigaciones evidencian los resultados positivos del proceso de formación de etnoeducadores, los cuales han realizado proyectos de participación y autogestión de las comunidades.

Palabras- clave: Etnodesarrollo. Amazonia. Educación.

\section{INTRODUÇÃO}

\section{A História da Educação Ocidental e a Implantação dos Sistemas Escolares Ocidentais na Amazônia Paraense}

É importante destacar que quando nos referimos à História da Educação no Brasil ou História da Educação na Amazônia, estamos tratando da implantação e/ou institucionalização da educação ocidental nos diferentes territórios e espaços definidos como espaços de educação formal e informal. Assim como no contexto nacional, a educação na Amazônia passou por inúmeras transformações influenciadas pelos modelos de desenvolvimento econômico instaurados nos diferentes períodos históricos, configurando, a cada período, as formulações e diretrizes de ensino.

Neste tópico serão discutidos os aspectos mais importantes da história da educação escolar no Brasil, desde o período colonial até o final do regime militar, buscando estabelecer uma ligação entre cada período histórico e a legislação educacional em vigor. A história da educação Brasileira costuma ser dividida pelos estudiosos nas seguintes etapas: Período colonial (1549 a 1808), Presença da família real no Brasil (1888 a 1822), Império (1822-1889), Primeira Republica (1889 a 1930), Era Vargas (1930 a 1945); República Populista (1945 a 1964); Regime Militar (19664 a 1985), Retorno da Democracia (1985 à atualidade) (ARANHA, 2006). 
A educação no período colonial é marcada pela atuação Jesuítica na colônia. De acordo com Chambouleyron (2018) além da conversão dos povos indígenas, o ensino das crianças foi uma das principais preocupações dos padres da Companhia de Jesus. A educação elementar foi inicialmente formada para os povos indígenas, mais tarde estendeu-se aos filhos dos colonos. $\mathrm{O}$ ensino das crianças indígenas se apresentava como uma forma de se estabelecer alianças entre os povos indígenas e os Jesuítas. Predominando no século $\mathrm{XVI}$, de acordo com o autor, a ideia de que as crianças eram uma nova cristandade.

Explicitamente, a missão da Companhia de Jesus era a de catequizar, ou seja, conseguir adeptos à fé católica, tornar os índios mais dóceis e submissos, para atuarem como mão de obra. Os indígenas eram vistos como vassalos do rei. Com a expulsão dos Jesuítas da colônia em 1759, o Marques de Pombal, realizou reformas educacionais que repercutiram no Brasil. Tirou o poder educacional da Igreja e colocou-o nas mãos do Estado. O ensino continuou enciclopédico, com objetivos literários e com métodos pedagógicos autoritários e disciplinares, abafando a criatividade individual e desenvolvendo a submissão às autoridades e aos modelos antigos. O objetivo do Marques de Pombal era formar súditos fiéis do rei de Portugal ((DOMINGUES, 2000; FARAGE, 1991).

Com a presença de D. João VI no Brasil durante mais de uma década, verificaram-se mudanças no quadro das instituições educacionais da época, com a criação do ensino superior não religioso: Academia Real da Marinha, Academia Real Militar, os cursos médico-cirúrgicos, a presença da Missão Cultural Francesa, a criação do Jardim Botânico, do Museu Real, da Biblioteca Pública e da Imprensa Régia. Relevantes por serem os primeiros centros de educação e cultura do Brasil, não deixaram de revelar as intenções aristocráticas de D. João, pois o ensino primário foi esquecido e a população em geral continuou iletrada e sem acesso aos grandes centros do saber.

A década de 1920 caracterizava-se pelo declínio das oligarquias, com a crise do modelo agráriocomercial-exportador e o impulso à industrialização com o modelo nacional-desenvolvimentista. A queda da oligarquia e a ascensão da burguesia industrial, as revoluções, o Tenentismo, o Partido Comunista e a Semana de Arte Moderna. Aas linhas de pensamento filosófico ligados à Escola Nova ${ }^{3}$ e dos católicos, vão ser incorporados à educação e influenciarão toda a organização escolar neste período.

O período Vargas é marcado pela prevalência do ensino profissionalizante. reformas no ensino secundário e indústria ação regulamentadas. Na década de 1960, determinados setores da sociedade voltaram-

\footnotetext{
${ }^{3}$ A Escola Nova foi um movimento ocorrido na primeira metade do século XX, de renovação do ensino que foi especialmente forte na Europa, na América e no Brasil, na primeira metade do século XX. Os teóricos da Escola Nova acreditam que a educação é o elemento eficaz para a construção de uma sociedade democrática, que leva em consideração as diversidades, respeitando a individualidade do sujeito, aptos a refletir sobre a sociedade e capaz de inserir-se nessa sociedade. O idealizador desse movimento na América foi o filósofo e pedagogo Norte-Americano John Dewey (18591952). Para ele a função da escola é propiciar uma reconstrução permanente da experiência e da aprendizagem dentro da vida do aluno. Então, para ele, a educação teria uma função democratizadora de igualar as oportunidades (Aranha, 2006).
} 
se para a educação popular, surgindo então os chamados Movimentos de Educação Popular (Centros Populares de Cultura - CPC - ligados à União Nacional dos Estudantes; Movimento de Educação de Base - MEB - ligado à Conferência Nacional dos Bispos do Brasil; e os Movimentos de Cultura Popular) que propunham levar ao povo, elementos culturais como teatro, cinema, artes plásticas; além de alfabetizá-lo e fazer com que a população adulta participasse ativamente da vida política do país (PAIVA, 1973).

Em 1964, ocorre o golpe de estado e os militares assumem o poder, ligados a grupos empresariais e políticos tendentes ao capital e interesses estrangeiros, notadamente norte-americanos. Num período inicial, empenharam-se à recuperação econômica, e a partir de 1967/1968, retomaram um acentuado desenvolvimento do setor industrial. Marcado por uma reforma universitária e criação de um acordo entre o Ministério da Educação (MEC) o Agência Americana para o desenvolvimento (USAID) com o Ministro da Educação Jarbas Passarinho que estabeleceu o decreto Lei 477 que dava as autoridades educacionais o poder de demitir professores, técnicos e alunos envolvidos em atividades consideradas subversivas pelo ensino profissional. A História da Educação do campo institucional no contexto amazônico passou pela: 1) prática extrativista, na qual ofertava-se para poucos grupos o curso primário de 4 anos, com poucas habilidades para além da leitura, escrita e matemática; 2) pelo modelo educacional do período militar no auge da urbanização e explosão das massas por vagas nas escolas nos anos 1970 e 1980; 3) ao ensino nas escolas públicas e privadas (LOUREIRO, 2007).

As décadas de 1970 e 1980, marcadas pelo modelo militar e aprovação da Lei de Diretrizes e Bases (LDB/71), representaram, na prática, um contexto marcado pela deterioração do ensino público, aumento do abandono da escola, ampliação das desigualdades sociais e acentuação das desigualdades regionais, falta de acesso à escola, má qualidade de ensino oferecido, além da falta de estrutura, transporte e material didático. No entanto, a partir da década de 1990, após forte mobilização de diversos seguimentos sociais, aprovam-se uma série de medidas legais que resultaram em grandes mudanças na educação brasileira até o momento atual, dentre as quais, destacam-se a aprovação do Fundo de Manutenção do Desenvolvimento do Ensino Fundamental e de Valorização do Magistério (FUNDEF), nova Lei de Diretrizes e Bases para a Educação Nacional (LDB/96), além da interiorização do Ensino Superior (LOUREIRO, 2007).

Neste artigo, tratamos especificamente dos reflexos deste contexto para a ensino superior de povos e comunidades tradicionais da Amazônia paraense. Sobretudo a partir da análise da política afirmativa na modalidade de curso especial, destinado à inclusão de discentes oriundos de povos e comunidades tradicionais no Curso de Licenciatura em Etnodesenvolvimento. É valido ressaltar que para a construção da análise deste artigo, contou-se com a participação ${ }^{4}$ de discentes do Curso de Etnodesenvolvimento (2019), por meio da

\footnotetext{
${ }^{4}$ Atendendo às questões éticas exigidas, os discentes participantes assinaram o MODELO DE TERMO DE CONSENTIMENTO LIVRE E ESCLARECIDO - TCLE, baseado nas DIRETRIZES CONTIDAS NA RESOLUÇÃO CNS Nº66/2012, MS.
} 
leitura e avaliação do conteúdo, do fornecimento dos dados e análises dos Relatórios de Tempo Comunidade desenvolvidos por eles nos períodos de setembro a dezembro de 2019 e março a maio de 2020.

\section{OS MOVIMENTOS SOCIAIS E AS POLÍTICAS AFIRMATIVAS PARA POVOS E COMUNIDADES TRADICIONAIS}

Em termos de movimento indígena, a década de 1970 é considerada um marco para os casos de reafirmação das identidades étnicas e da luta pelos direitos, enquanto sujeitos étnicos diferenciados frente ao Estado e à sociedade. Povos que devido ao processo de colonização, que culminou na desestruturação de suas culturas e do modo de vida indígenas, em alguns casos deixaram de ser reconhecidos como indígenas pelo Estado e pela sociedade nacional. Passam, na segunda metade do século XX, a reivindicar o reconhecimento de suas identidades e de seus direitos enquanto povos indígenas.

Nesse período, essas reivindicações do reconhecimento da identidade étnica tornam-se mais frequentes em relação às décadas anteriores. Também ganha força a criação dos movimentos indígenas, organizados a partir de articulações políticas entre povos de diferentes etnias, em defesa de seus direitos comuns, tais como: terra, saúde, educação etc.

A Década de 1970 é caracterizada, também, pelo apoio de setores progressistas da Igreja Católica aos movimentos sociais indígenas como o Conselho Indigenista Missionário (CIMI) que, nesse contexto, torna-se um aliado importante dos movimentos sociais, passando a ter o papel político de articular, apoiar, divulgar e denunciar questões relativas aos direitos indígenas. $\mathrm{O}$ fortalecimento dos movimentos indígenas ocorre a partir da realização de assembleias organizadas pelo CIMI e pela ascensão de lideranças indígenas com projeção nacional e internacional, as quais impuseram o surgimento de organizações indígenas regionais e nacionais (LUCIANO 2006).

Para Luciano (2006), foi devido à articulação do movimento indígena no âmbito nacional que avanços se tornaram possíveis no que diz respeito ao reconhecimento dos direitos indígenas garantidos na Constituição de 1988. Com a promulgação desse instrumento legal, inicia-se uma nova fase no movimento social indígena, pois foram implementadas mudanças na forma jurídica e política de inserção dos povos indígenas pelo Estado Brasileiro. Os Artigos 231 e 232 (Título VIII, Capítulo VIII Dos Índios) reconhecem legalmente os povos indígenas como integrantes da sociedade brasileira. Dessa forma, a década de 1980 caracteriza-se pela ampliação da relação do Estado com os povos indígenas a partir da criação de vários órgãos e ministérios indígenas, devido às conquistas a partir da Constituição de 1988. Em termos de organizações indígenas, verificou-se a formação de organizações informais politicamente ativas, mas pouco institucionalizadas, que reivindicavam seus direitos territoriais e assistência através da ação de lideranças tradicionais das aldeias.

A partir da década de 1990, os povos indígenas passam a dialogar com múltiplos interlocutores, uma vez que a Fundação Nacional do Índio (FUNAI) deixa de ser o único órgão responsável pela política indigenista com a redistribuição de suas responsabilidades com outros órgãos do governo brasileiro. Com essa 
redistribuição de competências, as questões relacionadas à saúde indígena passaram a ser de competência da Fundação Nacional de Saúde (FUNASA) e a educação escolar indígena passa para o Ministério da Educação (MEC), ficando a cargo da FUNAI, entre outras obrigações, a de identificação e demarcação das terras indígenas (MATOS, 2006).

Na década de 1990, ocorreu a multiplicação das organizações indígenas formais, institucionalizadas e legalizadas em todo o Brasil. As associações indígenas assumiram o papel que o Estado deixou de desempenhar em questões relacionadas à saúde, educação e terra, tornando-se um meio de lutar pelas demandas indígenas frente ao Estado e aos órgãos indigenistas oficiais. A partir do início do ano 2000, aumenta o número de representantes de movimentos indígenas, trabalhando nas esferas administrativas e ocupando funções políticas. Além disso, o início desta década é marcado por importantes conquistas políticas e de direitos como, por exemplo, a ratificação da Convenção 169 da Organização Internacional do Trabalho (OIT) no ano de 2002.

No início do século XXI, assistiu-se à emergência de uma política de reconhecimento dos direitos das minorias, corrida mundialmente, com base na diversidade dos povos. Esse reconhecimento legal dos direitos de povos indígenas no Brasil iniciou-se ainda no século passado, com a Constituição Federal de 1988, e ganhou força com a ratificação da Convenção 169 da OIT pelo governo brasileiro no ano se 2002, ocasionando o aumento de organizações sociais criadas com base em questões ligadas à identidade étnica, a exemplo dos povos indígenas e das comunidades quilombolas.

A partir da adoção da Convenção 169, como medida complementar à Constituição de 1988, em relação aos povos e comunidades tradicionais, a autodesignação torna-se suficiente para garantir o amparo desses povos pelo instrumento jurídico internacional. De acordo com Shiraishi Neto (2007), a Convenção 169 representa uma mudança radical, pois o pressuposto a ser considerado é o princípio da diversidade cultural e da autodeterminação, o que elimina a ideia de tutela pelo Estado. Assim não é mais necessário que o Estado ou os órgãos indigenistas estabeleçam quem é ou não oriundo de povos e comunidades tradicionais, pois eles podem falar de si próprios, assumindo, assim, o protagonismo na garantia de direitos. $\mathrm{O}$ avanço da Convenção 169 também está no fato de que ela rompe com uma visão universalista do direito, pois, ao reconhecer o caráter multiétnico das sociedades, abre possibilidades de interpretações jurídicas estabelecidas com base na vivência dos povos e comunidades tradicionais.

A adoção dos instrumentos internacionais pelo governo brasileiro, a exemplo da Convenção 169, pautada no critério da autoidentificação, fortaleceu as mobilizações dos povos e comunidades tradicionais, pois, ao terem reconhecidas suas especificidades, passaram a ter um respaldo legal para garantir suas reivindicações.

No âmbito educacional as conquistas foram a criação de reservas de vagas para povos e comunidades tradicionais nas universidades Federais do Brasil. De acordo com Beltrão e Cunha (2011) o processo seletivo especial para povos indígenas, aprovado pela Resolução $N^{\circ}$. 3.689/2009, consiste na reserva de duas vagas para povos indígenas em todos os cursos de graduação. Diferentemente do sistema de cotas que destina parte 
das vagas do vestibular para os grupos com vulnerabilidade social, as vagas para povos indígenas são acrescidas às vagas existentes e, caso não sejam ocupadas via processo seletivo diferenciado, são extintas. Sob nenhum argumento, as vagas reservadas podem ser ocupadas por estudantes não-indígenas.

As reservas de vagas são resultado das reivindicações dos povos indígenas no campo educacional e, ao mesmo tempo, evidencia o esforço institucional da Universidade Federal do Pará (UFPA) em alterar a situação de vulnerabilidade de determinados grupos sociais, ela foi criada pela resolução $\mathrm{n}^{\circ} 3.689$, de 22 de junho de 2009, do Conselho Superior de Ensino, Pesquisa e Extensão (CONSEPE), que aprovou a reserva de duas vagas, por acréscimo, em todos os cursos de graduação da Instituição, mediante seleção diferenciada.

Pela Reserva de Vagas foram criadas 2 vagas para povos indígenas em cursos de graduação da UFPA. Como parte das ações afirmativas da UFPA foi criado o curso de Etnodesenvolvimento, para atender as demandas de povos e comunidades tradicionais da região Amazônica como um todo, do qual nos deteremos a seguir.

\section{BREVE HISTÓRICO DA FACULDADE E CURSO}

O Curso de Licenciatura e Bacharelado em Etnodesenvolvimento faz parte da Faculdade de Etnodiversidade, subunidade do Campus Universitário de Altamira/Universidade Federal do Pará, juntamente com o curso de Licenciatura em Educação do Campo. Os cursos da Faculdade de Etnodiversidade desenvolvem suas atividades com base na Pedagogia da Alternância (que privilegia calendários diferenciados, divididos entre Tempo Universidade e Tempo Comunidade, como espaços indissociáveis do processo de formação), destinados a povos indígena, quilombolas e comunidades tradicionais. Ambos os cursos foram reconhecidos pelo MEC com notas 4 e 5, respectivamente, o que mostra a excelência desses cursos, sendo referências nacionais para a formação de professores.

Além dos dois cursos de Graduação, também ofertamos em conjunto com a Escola de Aplicação da UFPA/Belém, o curso Técnico em Magistério - Formação de Professores Extrativistas da Terra do Meio, em Altamira, Pará, além de pós-graduação Lato Sensu, ofertada pela faculdade, como a "Educação por Inversão Pedagógica: inclusão para a emancipação em territórios socioeducativos da Transamazônica e Xingu”, e outras em parceria com subunidades do Campus, como a Faculdade de Educação e Letras.

A estrutura curricular do Curso de Etnodesenvolvimento e Educação do Campo inclui atividades desenvolvidas nas comunidades originárias dos discentes, chamadas Tempo-Comunidade, orientadas pelos docentes. Nesses momentos, os discentes e agentes sociais são convidados a refletir acerca de suas realidades, considerando o necessário diálogo entre os saberes local e acadêmico. Do diálogo surgem propostas de intervenção, pensadas a partir dos próprios sujeitos de interesse: os comunitários.

O Curso de Etnodesenvolvimento foi pensado para atender as demandas de qualificação profissional de povos e comunidades tradicionais. O objetivo do curso é formar agentes de etnodesenvolvimento, para que 
possam trabalhar em suas comunidades de origem intervindo em instâncias internas e externas e na elaboração de projetos de intervenção que possa beneficiar toda a comunidade.

O curso a princípio havia sido pensado para exclusivamente para povos Indígenas, porém após discussão com os movimentos sociais, chegou-se a concussão de que havia a necessidade de se incluir os demais grupos de pertenças tais como: comunidades quilombolas, ribeirinhos, agricultores familiares, extrativistas, pescadores e pessoas oriundas do movimento negro, pois acredita-se que essas comunidades e grupos étnicos raciais também têm o direito de acessar as universidades públicas via políticas afirmativas, uma vez que também passaram pelo mesmo processo de exclusão social ao longo da história do Brasil que os povos indígenas. Dessa forma a estrutura curricular do curso de Etnodesenvolvimento é pensada para atender as demandas de todo o público que compõe o curso. As discussões levantadas em sala de aula têm por base a diversidade étnica e racial dos discentes do curso.

A estrutura curricular do Curso é baseada na Pedagogia da Alternância, em que há o período do TempoUniversidade, sempre em regime intervalar (janeiro e fevereiro; julho e agosto) em que os discentes participam das disciplinas curriculares, e o período do Tempo-Comunidade, no qual os discentes retornam aos grupos de pertença para realizar atividades previamente planejadas de pesquisa, extensão e ensino, e que são monitoradas pelos docentes. Neste artigo falaremos mais detidamente do Tempo-Comunidade, e sua importância para a formação profissional e política dos estudantes, assim como para a interação entre a universidade e as comunidades tradicionais.

No que diz respeito ao Tempo-Comunidade, é o momento no qual os discentes retornam para as suas comunidades e nelas desenvolvem suas atividades acadêmicas depois do semestre letivo na universidade. $\mathrm{O}$ Curso ocorre no regime intervalar, portanto, os alunos cursam as disciplinas do percurso curricular nos meses de janeiro/fevereiro e julho/agosto. O Tempo-Comunidade é acompanhado por um docente do Curso, que vai até a comunidade para orientar os discentes nas atividades, assim como conhecer a realidade da comunidade do discente, o que possibilita pensar as aulas dos semestres posteriores, tendo em mente a realidade do aluno.

Uma vez que, as disciplinas do Tempo Universidade são pensadas a partir dos resultados das pesquisas realizadas pelos alunos nos Tempos Comunidades. São a partir dos problemas e questões levantados pelos alunos em suas pesquisas que são feitas pensados e discutidas as questões étnicos-raciais envolvendo cada grupo de pertença que faz parte do curto. Atualmente o curso conta com uma parcela significativa de alunos quilombolas da região do Marajó, e é a partir dos dados levantados pelos alunos em sua comunidade e em partir no ambiente escolar das comunidades que as discussões raciais são feitas, unindo os conhecimentos tradicionais e as experiencias de vida dos alunos com o conhecimento científico, para que possam ser tomadas juntamente com a comunidade estratégias de luta por direitos e de resistência contra o preconceito sofridos pela população negra e pelos descendentes de povos escravizados.

O Projeto Político Pedagógico do Curso de Licenciatura e Bacharelado em Etnodesenvolvimento foi aprovado pela resolução N. 3.861 de 22 de maio de 2009, formulado com base na RESOLUÇÃO CNE/CP 
$\mathbf{N}^{\mathbf{0}}$ 1, de 18 de Fevereiro de 2002, que institui Diretrizes Curriculares Nacionais para a Formação de Professores da Educação Básica, em nível superior, curso de licenciatura, de graduação plena.

O Projeto Político Pedagógico do Curso de Etnodesenvolvimento aprovado estrutura as disciplinas a partir do eixo central da Diversidade Cultural, dividido em sete núcleos de disciplinas: Sistemas de Saúde; Educação; Direitos Humanos; Sociedade e Meio Ambiente; Desenvolvimento e Sustentabilidade; Identidade, Nação e Território; Linguagens Étnicas; Atividade Complementar. As atividades do Curso são todas pensadas a partir da realidade do aluno, de forma a aliar os conhecimentos tradicionais com o conhecimento científico. O Curso é formado por alunos das seguintes pertenças: indígenas, quilombolas, ribeirinhos, agricultores familiares rurais, pescadores, extrativistas e movimentos sociais

De acordo com a resolução de 18 de fevereiro de 2002, os egressos do curso de Etnodesenvolvimento estão aptos a atuar como licenciados na educação básica. No entanto, o PPC do curso não especifica em quais disciplinas os egressos do curso podem atuar no ensino básico. A primeira turma egressa concluiu o curso em janeiro de 2015. Atualmente o curso conta com duas turmas formadas (Turmas 2010 e 2013) e três turmas em formação (Turma 2015 e 2019, em Altamira) e a turma 2016, flexibilizada para o Campus da UFPA em Soure.

A formação dos egressos dos cursos e sua atuação como docentes, uma vez inseridos no mercado de trabalho, se relaciona com diversos dispositivos legais, que garantem à população o acesso à educação. Primeiramente, a Constituição Federal de 1988 afirma, em seu artigo 205, que a educação é direito de todos e dever do Estado. A partir daí, há vasta gama de legislações garantindo o direito à educação a partir de uma perspectiva de respeito à diferença: o Plano Nacional de Educação (Lei $\left.n^{\circ} 13.005 / 2014\right)$, art. 8, $\S 1^{\circ}$, inciso II; o Programa Nacional de Educação na Reforma Agrária (Decreto n ${ }^{\circ} 7.352 / 2010$ ), em seu artigo $1^{\circ}$ e seguintes; a Portaria MEC nº 86/2013 (Programa Nacional de Educação no Campo), a Resolução do Conselho Nacional de Educação n ${ }^{\circ}$ 01/02 (Institui as Diretrizes Operacionais para a Educação Básica nas Escolas do Campo); bem como a Convenção 169, a qual foi inserida no ordenamento jurídico pátrio através do Decreto 5.051/04, que afirma expressamente o direito à educação etnicamente diferenciada e culturalmente relevante.

No ano de 2015, o Ministério da Educação lançou uma nova resolução (Resolução no ${ }^{\circ}$, DE $1^{\circ}$ de julho de 2015) que define as Diretrizes Curriculares Nacionais para a formação inicial em nível superior (cursos de licenciatura, cursos de formação pedagógica para graduados e cursos de segunda licenciatura) e para a formação continuada. De acordo com as diretrizes traçadas por esta resolução, a carga horária do curso de Etnodesenvolvimento não habilitaria os docentes do curso para atuar na educação básica. Também ficou estabelecido a divisão entre as habilitações licenciatura e bacharelado, assim os cursos de graduação não poderiam mais ofertar a dupla titulação.

Dessa forma, o curso de Etnodesenvolvimento teria que se adequar as normativas do MEC e com a formulação e aprovação de um novo Projeto Político e Pedagógico do Curso (PPC). A proposta do colegiado do curso foi formular o novo PPC juntamente com as comunidades a partir das turmas que já estavam no curso. Porém a ideia de que os egressos do curso não poderiam receber a dupla titulação (Licenciatura e Bacharelado) 
criou grande insatisfação entre os estudantes e egressos do curso, e resultou em diversos processos no Ministério Público Federal (MPF). Os estudantes alegavam que apenas uma titulação não atenderia as demandas de suas comunidades.

A partir do MPF os egressos do curso e as turmas que ainda estavam cursando conseguiram que em seus diplomas continuassem constando a titulação em Licenciatura e Bacharelado. Porém a partir da formação de um novo PPC o curso teria que optar por uma das habilitações. Depois um longo processo de discussões com os estudantes e professores do curso optou-se pela habilitação em licenciatura. Uma vez que, após pesquisa realizada entre os alunos egressos do curso constatou-se que os mesmos estavam atuando, a maioria nas escolas de sua comunidade.

Dessa forma, foi aprovada a resolução n. 6124 de 32 de janeiro de 2019, de acordo com a qual o objetivo do curso é formar profissionais para atuar na área de ensino de Etnodesenvolvimento com ênfase nas áreas das Ciências Humanas e sociais, exercendo a docência das disciplinas Filosofia, Sociologia, História e Geografia, bem como na gestão e organização do trabalho pedagógico escolar. O estudo de caso do curso de Etnodesenvolvimento mostra a necessidade de um constante diálogo com as comunidades na tomada de decisões referentes à educação. Ao mesmo tempo deixa claro que o diálogo embora tenha se mostrado o melhor caminho, não é o mais fácil, pois as comunidades e os sujeitos envolvidos nas discussões possuem opiniões muitas vezes divergentes.

O diálogo com os estudantes do curso e com suas comunidades de origem tem se mostrado muito rico para a experiência pedagógica do curso e nas tomadas de decisões. A partir das pesquisas dos tempos comunidades, como mostraremos ao longo do artigo, os estudantes, a partir dos dados coletados em seus locais de origem, apontam diversos problemas enfrentados nas escolas locais, as quais em sua grande maioria não considera as questões étnicas e raciais dos estudantes e empoem modelos educacionais generalizados que não condizem com a realizada dos estudantes e de suas comunidades. Assim, os debates em sala de aula têm proporcionado um maior diálogo entre docentes e discentes do curso.

\section{RESULTADOS E DISCUSSÕES}

Em síntese, a formulação das Diretrizes Curriculares do Curso de Licenciatura em Etnodesenvolvimento, a partir da oposição ao caráter colonial e hegemônico do conhecimento científico com o reconhecimento e formalização das reivindicações de grupos sociais diferenciados, integra políticas afirmativas e baseia-se na oferta de uma Educação Plural, Multicultural, Intercultural, Diversa e Diferenciada, pensada nas diferentes expressões e práticas. A partir da proposição de uma formação profissional em nível superior com atividades de ensino, pesquisa e extensão, e com articulação entre teoria e prática. Do mesmo modo, propõe-se trabalhar de forma interdisciplinar, com avaliação como princípio educativo; educação continuada; múltiplas linguagens; adoção de práticas metodológicas participativas; gestão democrática; liberdade de pensamento; à educação pública, gratuita e de qualidade social. 
Neste artigo, de forma específica, organizamos uma breve análise acerca de um dos componentes curriculares essenciais do curso, o "fazer didático-pedagógico". Adequando-se à Lei de Diretrizes e Bases da Educação Nacional (LDBN) n 9 9.394/96, a qual reconhece 400 (quatrocentas) horas de prática para a formação docente.

A seguir, apresentaremos algumas das reflexões sistematizadas pelos discentes da turma de Etnodesenvolvimento/2019 nos relatórios produzidos nos períodos Comunidade 1 e 2, nos quais realizaramse pesquisas qualitativas e coletaram-se dados acerca da História e Educação nas comunidades de pertença.

\section{Análise acerca da História da Educação a Partir das Pesquisas de Campo dos Discentes do Curso de Etnodesenvolvimento/2019}

De acordo com os próprios discentes, pertencentes a comunidades quilombolas, indígenas, ribeirinhas, de reservas extrativistas e do campo, a escola, nos diferentes territórios e com as diversas pertenças, consiste em um espaço de conquista sobre: 1) o direito ao reconhecimento do ensino instituído como "formal" pelo sistema de ensino ocidental; 2) da disputa entre modelos de educação exógenos e endógenos; 3) da luta cotidiana para garantia das condições materiais e de infraestrutura para o funcionamento do ano letivo.

No entrelaçar desses fatos, para além da demanda estrutural e econômica em relação à escola, pode-se refletir sobre a disputa de projeto político e pedagógico, sobretudo para a incorporação de currículos sobre a perspectiva dos grupos étnicos e raciais em contraste com os planos construídos por equipes técnicas das esferas públicas do setor educacional. O discurso da disputa entre projeto de ensino, formação de professores e currículo escolar torna-se explicito nos relatos extraídos pelos discentes durante as pesquisas de campo nas suas comunidades de pertença, e possibilitam a sistematização e a problematização de diversos problemas e demandas locais acerca da educação e outros temas incorporados ao currículo do curso.

\section{Do Direito à Escola para a Luta por Educação Multicultural e Diferenciada para Povos Indígenas, Comunidades Negras e Quilombolas e demais Comunidades Tradicionais}

De forma recorrente os discentes pesquisadores descrevem práticas contraditórias nos processos de promoção do direito à educação nas suas comunidades. Criticam o sistema escolar vigente, o qual funciona a partir da prestação de contas de um calendário e projeto pedagógico que não contemplam as necessidades da comunidade. A narrativa dos comunitários entrevistados denuncia a atuação dos órgãos públicos de educação apenas para o cumprimento das leis no papel, sem compromisso com a realidade e necessidade local.

Luiz Munduruku, da Aldeia Missão São Francisco, na região do Tapajós, ao relatar sobre a história da educação na sua comunidade de pertença, organiza os fatos a partir de três momentos históricos: 1) a "chegada" da educação; 2) o reconhecimento pelo Estado da escola na comunidade como espaço de educação escolar formal; 3) a luta do seu povo pela efetivação ao direito de uma educação diversa e que mantenha os modos de 
vida Munduruku. O texto escrito pelo discente indígena, descreve a concepção de que a educação consiste apenas como um direito reconhecido pelo sistema escolar ocidental, ou como uma prática exercida por missionários religiosos para o seu povo, tendo em vista que afirma que "a educação começou desde a chegada das irmãs na comunidade" (MUNDURUKU, 2020, p.3).

Sobre o processo de reconhecimento formal do espaço da escola, Luiz narra uma articulação jurídica pela responsabilidade da gerencia e destinação dos recursos da escola local pelos órgãos do Estado, os quais garantem a estrutura e modernização do espaço. No entanto, no que se refere à oferta de ensino diferenciado e à garantia do direito a manutenção dos modos de vida tradicionais por meio da educação, pouco se avança, conforme afirmação a seguir:

Hoje em dia, a escola da aldeia é do município. Por isso sempre, tudo a escola, foi autorizado pela secretária de educação do município, e não tem nenhuma escola para o acesso à educação diferenciada. E também a educação está sempre desenvolvendo em cada ano e modernizando na aldeia, por conhecimento tecnológica, cada as escolas, sempre recebe a tecnologia como: o computador, a impressora, o data show e a via satélite, como o Internet. E avanço o conhecimento dos alunos, mas hoje em dia, o administrador do município, não se interessam os problemas relativos à educação como a reforma da escola, abastecimento de água e sistema de acesso e transporte escolar (MUNDURUKU, 2020, p.5).

\section{Demandas Estruturais e Falta de Professores nas Comunidades}

Outra demanda elencada pelos discentes consiste na carência de professores nas escolas das comunidades, tendo em vista que as localidades estão distantes da área urbana e dependem das estruturas públicas para a locomoção e permanência dos profissionais nas escolas dos contextos do campo, água e floresta. De acordo com a pesquisa do discente Higor Cazimiro, pertencente a Reserva Extrativista (RESEX) Rio Xingu, em Altamira, Pará, a qual é formada por pessoas de baixa renda, na sua maioria de negros que vivem da pesca e extrativismo, o contexto educacional local é marcado pela falta de estrutura e de profissionais, o que compromete o próprio funcionamento das escolas, conforme trecho a seguir:

Os professores chegam no mês de abril nas escolas, sendo que as aulas na cidade começam em fevereiro. Atualmente o estado não oferece o ensino médio nessas escolas, muitas delas só vão até o $5^{\circ}$ ano do ensino fundamental, só funciona o sistema modular na comunidade Baliza, que vai do $6^{\circ}$ ao $9^{\circ}$ ano. O sistema de transporte escolar é via fluvial que funciona muito bem, mas segundo o entrevistado 6, a secretaria de educação não faz o pagamento desses barqueiros em dias, até chegar ao ponto de os mesmos ficarem paralisados até que a mesma faça o pagamento, para comprar combustível (CAZIMIRO, 2019, p.07).

No relatório produzido pelo discente Herlan Silva, pertencente a mesma RESEX que o Higor, as problemáticas referentes à educação e saúde resultam da saída das pessoas da comunidade para estudar na cidade, conforme explicitado no trecho a seguir:

A educação, juntamente com a saúde, é um dos principais problemas que não funcionam de forma esperada. Com isso, tem movido a população a abandonar a reserva à procura de melhores condições de vida para os filhos. Ainda existe crianças da comunidade que continuam sem estudar, em razão da distância da escola de sua localidade e o fato de professores só estarem ministrado as séries iniciais (SILVA, 2019, p. 24). 

cultura

Na comunidade ribeirinha Jarari em Porto De Móz, da qual a discente Jonara Maia pertence, a escola está desativada há cerca de 9 anos pelo mesmo motivo exposto por Higor e Herlan, a distância da cidade e a falta da atuação dos governos locais para o funcionamento da escola na comunidade, conforme relato abaixo:

Porto de Moz se recusa da assistência a educação escolar, por acreditar que é mais fácil uma parceria com Senador José Porfirio e deslocar os alunos para a cidade, que manter uma escola ativa no campo. A secretária de educação do município de Senador, deixou a disposição da comunidade uma lancha escolar, nos dias em que a tal lancha está quebrada a SEMED dispõe o combustível a cada família para trazerem os alunos de catraia, com essas dificuldades alguns alunos optam em morar no município com algum parente ou conhecido para estudar" (MAIA, 2019, p. 16).

Apesar da recomendação no artigo 26 da convenção 169 da OIT, sobre a adoção de medidas para garantia da educação aos membros da comunidade, com condições de igualdade e para todos os níveis em relação ao restante da comunidade nacional, $\mathrm{O}$ aluno Carlindo, da comunidade Pedra Roxa, localizada na Rodovia Transamazônica - BR230, Km 140, sistematizou os dados referentes ao nível de escolaridade e acesso dos moradores da escola local, a partir dos quais, apesar de todos as políticas e ações históricas no país e região, ainda é evidente o alto índice de analfabetismo e dificuldade do acesso à escola por jovens e adultos:

O nível de escolaridade entre os adultos acima de 50 anos é baixo, sabem apenas assinar o nome, cerca de $20 \%$ são analfabetos. Entre os jovens a maioria concluíram o ensino fundamental e uma pequena parte concluiu o ensino médio, entre as famílias entrevistadas, ninguém tem curso de nível superior (SILVA, 2019, p. 07).

A discente Neiva Gomes, da comunidade Santa Luzia, Quilombo de Flexinha, no município de Gurupá, Pará, descreve a seguir algumas das possíveis causas para a recorrente falta de infraestrutura e profissionais nas escolas de sua comunidade. Segundo a mesma, é possível afirmar que a mudança dos governos locais possui influência direta na condução dos projetos, na gestão e equipe da escola, que atualmente conta com uma gestão com pouca participação da comunidade:

Hoje o prédio escolar está comprometido devido à mesma nunca ter sido reformada, a educação na comunidade já teve melhor, até o ano de 2016 onde tudo funcionava de acordo com a comunidade, a partir daí com a troca do governo municipal e por questões políticas a equipe de professores que atuava foi demitida [...] Começaram surgir problemas que não se tinha antes, a secretaria de educação se omitiu em apresentar a nova equipe a comunidade, não houve reuniões dos professores com os pais, nem no início nem no termino do ano letivo, a nota da merenda e o calendário escolar não foram mais apresentados (GOMES, 2019, p. $10)$.

\section{Falta de Participação dos Comunitários na Construção do Projeto Político Pedagógico das Escolas Locais}

A OIT, no artigo 27, recomenda que haja cooperação e participação nos programas e serviços de educação dos povos para os quais são destinados, visando responder e resolver as necessidades particulares dos mesmos, além de abranger suas histórias, saberes e aspirações. No entanto, a participação dos membros da comunidade consiste em uma demanda expressiva dos relatórios dos discentes. Reivindica-se a construção 

cultura

e desenvolvimento do Projeto Político Pedagógico das escolas, considerando que a análise dos dados sobre a educação na comunidade revelou que poucos moradores conhecem e/ou nunca tiveram acesso aos documentos.

Um dos exemplos consiste no relato de um dos comunitários extrativista entrevistado pelo discente Herlan, ao afirmar que "o calendário escolar, currículo, material didático, merenda, já vem tudo pronto da cidade, não tem nenhuma reunião antes para ver o que seria melhor para os alunos" (SILVA, 2019, p. 20).

\section{O Currículo da Escola na Perspectiva Étnica e Multicultural}

Em concordância com a Convenção no 169 da Organização Internacional do Trabalho, no que tange a educação e comunicação de povos e comunidades tradicionais, do artigo 31 :

Deverão ser adotadas medidas de caráter educativo em todos os setores da comunidade nacional, e especialmente naqueles que estejam em contato mais direto com os povos interessados, com o objetivo de se eliminar os preconceitos que poderiam ter com relação a esses povos. Para esse fim, deverão ser realizados esforços para assegurar que os livros de História e demais materiais didáticos ofereçam uma descrição equitativa, exata e instrutiva das sociedades e culturas dos povos interessado" (ORGANIZAÇÃO INTERNACIONAL DO TRABALHO, 2002).

No entanto, a discente Neiva, ao relatar uma das ações da gestão da escola de sua comunidade, descreve uma prática não democrática e resultou na negação do direito à educação multicultural, tendo em vista que "a disciplina afro-brasileira que nos aproxima da história do povo quilombola mesmo que o currículo da mesma venha em questão nacional e não especifica somente a história do povo quilombola de Gurupá, foi substituída pelo inglês" (GOMES, 2019, p. 10).

Luiz Munduruku também apresentou uma reflexão interessante sobre a mudança no currículo ao longo dos anos de implantação dos sistemas de educação na aldeia Missão São Francisco, no Tapajós. O indígena destacou os métodos de educação das irmãs religiosas, através das aulas com ensinamento de cânticos cristãos, técnicas de costura, artes e estratégias econômicas para o uso do dinheiro. Consoante o discente, atualmente, após os anos de transição entre os sistemas escolares implantados na comunidade, compreende-se a necessidade de incorporação dos saberes ancestrais do seu povo no currículo da escola indígena.

Para a discente Jonara Maia, pertencente a uma comunidade ribeirinha no município de Porto de Móz, no Pará, o currículo escolar deve contemplar os saberes locais, sobretudo a partir das demandas e especificidades locais, conforme afirmação do seu relatório:

Tratando desde então da realidade educacional local, o ideal que a escola da comunidade voltasse a funcionar para trabalhar as especificidades do campo, a exemplo da pesca e agricultura, pois muitos alunos que estudam no Jarari, moram em roças e trabalham com este ramo, por exemplo, "horta" poderia valorizar as culturas cultivadas na região e ainda ajudar na merenda escolar. Outro fato importante a ser tratado aqui está relacionado à forma de aprendizagem das crianças antes de existir escola, a responsabilidade era das famílias em cuidar da educação e ensinamentos, as crianças aprendiam com os pais e membros da família sobre as atividades produtivas caça e pesca (MAIA, 2019, p. 16). 
Jonara, ao defender um currículo que contemple a realidade local, também constrói uma importante reflexão acerca do papel da educação escolar em relação a educação familiar, uma das questões marcantes no contexto de comunidades tradicionais. De acordo com a discente, com a chegada da escola na comunidade, difunde-se a concepção de educação hegemônica e ocidental que terceiriza e oferta o cargo de ensinar os conhecimentos, com base na ideia de que educação é papel da escola e deve ser ensinada na escola, ficando a cargo dos educadores.

Esta prática tem influência direta nos costumes tradicionais familiares, pois questiona-se sobre quem cuida da educação dos filhos e filhas dos comunitários, a escola ou a família? A escola deve ensinar os saberes locais ou os conteúdos de fora da comunidade? ou, ainda, quais conteúdos devem ser trabalhados e quem deve ensiná-los aos alunos, pessoas de dentro ou de fora da comunidade? No trecho a seguir, retirado do relatório da discente, é possível observar o discurso da disputa sobre os papeis da educação escolar e familiar:

\begin{abstract}
Atualmente não apenas a comunidade do Jarari, mas como também a sociedade em geral não participa diretamente da educação de seus filhos, deixando a responsabilidade em cima da escola... o conhecimento não nasce de um vazio e sim de experiência que acumulamos na vida cotidiana, as instituições escolares se preocupam em ensinar conhecimentos das disciplinas e informação do mundo e não levam em consideração os ensinamentos e aprendizados da vivencia familiar e o respeito ao mais velhos (MAIA, 2019, p.16).
\end{abstract}

Contribuições da formação docente em Etnodesenvolvimento para territórios quilombolas, indígenas e demais comunidades tradicionais

Para além da sistematização acerca das problemáticas locais e demandas das comunidades de pertença dos discentes em etnodesenvolvimento, ao longo dos 10 anos de curso, os projetos de intervenção e a atuação dos egressos e discentes nas comunidades tem resultado em ações transformadoras, sobretudo na área da educação. Um dos grandes exemplos consiste na formação de professores pelos magistérios nas comunidades extrativistas, a qual, além possibilitar a conclusão da educação básica aos comunitários, tem conseguido resolver uma das principais dificuldades vivenciadas por todos os grupos de pertença, a falta de permanência de professores para atuarem nas escolas do contexto do campo, floresta e água. Um dos exemplos desta ação é relatado pela discente Neiva, do Quilombo de Flexinha, a qual afirma que na sua comunidade "a escola conta hoje com dois barqueiros, uma merendeira, quatro professores, dos quais uma está sendo formada pelo Plano Nacional de Formação de Professores (PARFOR); um formado e outro cursando Educação no Campo e um professor tem somente o ensino médio" (GOMES, 2019, p.10).

Do mesmo modo, pode-se destacar ainda que o Curso de Etnodesenvolvimento possibilita a efetivação da proposta do Programa de Políticas Afirmativas para Povos Indígenas e Populações Tradicionais (PAPIT), tendo em vista que para algumas localidades o magistério resultou na fundação da escola, como no caso relatado pela discente da turma de 2019 Ngrenhdjãm Xikrin, pertencente a comunidade da Aldeia Kameredjãm, localizada na Terra Indígena Trincheira/Bacajá: 
A escola na aldeia foi construída pelas pessoas própria comunidade no ano de 2017 . No primeiro ano quem lecionava na escola era o professor indígena formado pelo magistério indígena Dênis Kayapó de Souza e no ano seguinte foi uma professora não indígena da cidade de Altamira graduada em pedagogia. Atualmente, sou eu professora indígena Ngrenhdjãm Xikrin graduanda do Curso de Licenciatura em Etnodesenvolvimento pela Universidade Federal do Pará (SILVA, 2019, p. 9).

Consequentemente, os professores formados pelos magistérios específicos para comunidades tradicionais têm conseguido contribuir com a construção e condução do PPP e calendário escolar, em parceria com a comunidade, outro grande desafio local. No caso relatado por Ngrenhdjãm "o calendário do povo Xikrin encontra-se no Projeto Político Pedagógico (PPP), mas o projeto político pedagógico do povo Xikrin foi discutido junto com lideranças e professores indígenas e a coordenação pedagógico da SEMED" (SILVA, 2019, p.9).

\section{CONSIDERAÇÕES FINAIS}

A partir das explanações e discussões acerca da configuração dos sistemas escolares nos territórios quilombolas, indígenas e das demais comunidades tradicionais de pertença dos discentes citados, é possível constatar que o curso de Etnodesenvolvimento, por meio do projeto pedagógico diferenciado, tem contribuído consideravelmente para a construção de experiências de educação contra hegemônica, diferenciada e multicultural, uma vez que nas narrativas dos discentes pesquisadores já se reconhecem os resultados da atuação dos etnoeducadores nas escolas das comunidades, através da promoção de projetos de intervenção local, atuação docente nos níveis de ensino da educação básica, participação e elaboração de projetos pedagógicos e de currículos diferenciados, além de experiências de gestão escolar.

É valido ressaltar que a sistematização dos dados acerca da realidade e história da educação local consiste no resultado do processo de formação docente de integração dos conhecimentos científicos com os tradicionais e da articulação entre teoria, prática e formação, de modo que os discentes pesquisadores passam pelo exercício de compreensão e afirmação da própria identidade de pertença como membro de comunidade tradicional; pelo conhecimento dos direitos às políticas afirmativas para a educação historicamente conquistadas; pela análise sobre os desafios do tempo presente como herança dos momentos históricos de implantação do sistema escolar vigente nas suas comunidades; da reflexão sobre os conhecimentos estudados em relação com os saberes, demandas e práticas locais; e da articulação de estratégias de intervenção na comunidade para o reconhecimento e garantia dos direitos locais. Esse processo tem contribuído para a permanecia e intervenção dos discentes nas comunidades durante a formação universitária e após a diplomação, invertendo a lógica de evasão do campo para a formação profissional de mercado no contexto urbano.

Entretanto, compreende-se que ainda existem muitos desafios para a efetivação das políticas educacionais afirmativas para povos quilombolas, indígenas e demais comunidades tradicionais, tendo em 
vista que nos relatórios constata-se demandas por vagas para membros de comunidades tradicionais em cursos de processos seletivos especiais e dos demais cursos regulares para os quais são reservadas poucas vagas; solicita-se a ampliação da reserva de vagas destinadas a indígenas e quilombolas para as demais pertenças de comunidades tradicionais (ribeirinhos, extrativistas, pescadores, agricultores e entre outros); evidencia-se dificuldades de acesso à informação por parte dos membros das comunidades em contraste com a pouca divulgação nos territórios dos processos seletivos especiais e demais políticas afirmativas para povos e comunidades tradicionais por parte das universidades; Solicita-se a ampliação de políticas e programas para a permanência dos discentes nos cursos como bolsas e auxílios de moradia e entre outros; além das demandas para a atuação profissional dos egressos por meio do reconhecimento do diploma do curso nos processos de contratação de pessoal e de concursos públicos, sobretudo para a atuação dos mesmos nos próprios territórios de pertença.

\section{REFERÊNCIAS}

ARANHA, Maria Lúcia de Arruda. História da educação e da pedagogia. São Paulo: Moderna, 2006.

BELTRÃO, Jane Felipe; CUNHA, Mainá, Jaison Sampaio. Resposta à diversidade: políticas afirmativas para povos tradicionais, a experiência da Universidade Federal do Pará" In Espaço Ameríndio (UFRGS), v. 5/3, 2011. pp. 10-38.

BRASIL. Decreto no 5.051, de 19 de abril de 2004. Convenção no 169 da Organização Internacional Do Trabalho - OIT sobre povos indígenas e Tribais. Brasília, DF: 2004 (revogado pelo Decreto 10.088, de 12 de novembro de 2019). Disponível em: < http://www.planalto.gov.br/ccivil_03/_ato20042006/2004/decreto/d5051.htm>. Acesso em: 3 nov. 2020.

CAZIMIRO, Higor Mathues Faustino. Relatório de Tempo Comunidade I. Relatório Realizado na Reserva Extrativista Rio Xingu, Altamira, Pará. Altamira: Faculdade de Etnodiversidade, Universidade Federal do Pará, 2019.

CHAMBOULEYRON, Rafael. Jesuítas e as crianças no Brasil quinhentista. In_: DEL PRIORE, Mary (Org.). História das crianças no Brasil. São Paulo: Contexto, 2018.p.55- 83.

DOMINGUES, Ângela. A transformação dos índios em vassalos. In: DOMINGUES, Ângela. Quando os índios eram vassalos. Lisboa: CNCDP, 2000. pp. 15-197

FARAGE, Nádia. As muralhas dos sertões: os povos indígenas no Rio Branco e a colonização. Rio de Janeiro: Paz e terra, 1991.

GOMES, Neiva Dos Santos. Relatório de Tempo Comunidade I. Relatório Realizado na Comunidade Santa Luzia, Quilombo de Flexinha. Altamira: Faculdade de Etnodiversidade, Universidade Federal do Pará, 2019.

LOUREIRO, Violeta Refalesky. Educação e sociedade na Amazônia em mais de meio século. Revista Cocar. v.1, n. 1. [s. 1.]: 2007. Disponível em: < https://periodicos.uepa.br/index.php/cocar/article/view/141>. Acesso em: 3 nov. 2020. 
LUCIANO, Gersem. Índio Brasileiro: o que você precisa saber sobre os povos indígenas no Brasil de hoje. Brasília: Ministério da Educação, Secretaria de Educação Continuada, Alfabetização e Diversidade; LACED/Museu Nacional, 2006.

MAIA, Jonara Pima. Relatório de Tempo Comunidade I. Análise socioeducativo, memória e economia da Comunidade do Jarari, Porto de Móz-Pará. Altamira: Faculdade de Etnodiversidade, Universidade Federal do Pará, 2019.

MATOS, Maria Helena Ortolan. Rumos do movimento indígena no Brasil contemporâneo: experiências exemplares no Vale do Javari. (Tese de Doutorado). Instituto de Filosofia e Ciências Humanas, Universidade Estadual de Campinas, Campinas, 2006.

MUNDURUKU, Luiz Akay. Relatório Tempo Comunidade II. Relatório Realizado na Comunidade Aldeia Missão São Francisco, Itaituba, Pará. Altamira: Faculdade de Etnodiversidade, Universidade Federal do Pará, 2020.

OLIVEIRA, Assis; BELTRÃO, Jane. Etnodesenvolvimento \& universidade: formação superior para povos e comunidades tradicionais.Belém: Gráfica e Editora Santa Cruz, 2013.

PAIVA, Vanilda. Educação popular e educação de adultos. São Paulo: Loyola, 1973. 368 p.

SHIRAISHI NETO, Joaquim. A particularização do universal: povos e comunidades tradicionais em face das declarações e convenções internacionais. In: Direito dos povos e das comunidades tradicionais no Brasil: declarações, convenções internacionais e dispositivos jurídicos definidores de uma política nacional. Manaus: UEA, 2007. p. 25-52.

SILVA, Carlindo Lima da. Relatório de Tempo Comunidade I. Relatório Realizado na Comunidade Pedra Roxa, Uruará, Pará. Altamira: Faculdade de Etnodiversidade, Universidade Federal do Pará, 2019.

SILVA, Herlan Barbosa. Relatório de Tempo Comunidade I. Relatório Realizado na Reserva Extrativista Rio Xingu, Altamira, Pará. Altamira: Faculdade de Etnodiversidade, Universidade Federal do Pará, 2019.

SILVA, Ngrenhdjãm Xikrin. Relatório de Tempo Comunidade I. Relatório Realizado na Terra Indígena Tricheira/Bacajá, Anapu, Pará. Atamira: Faculdade de Etnodiversidade, Universidade Federal do Pará, 2019.

UNIVERSIDADE FEDERAL DO PARÁ. Projeto Pedagógico do Curso de Etnodesenvolvimento. Altamira, [entre 2010-2010]. 